\title{
EL PROCESO DE RENOVACIÓN DE LA OFERTA DE ALOJAMIENTO TURÍSTICO EN DESTINOS CONSOLIDADOS: EL CASO DE PUERTO DE LA CRUZ $(1955-2009)^{1}$
}

Agustín Dorta Rodríguez.

Universidad de La Laguna

\section{RESUMEN}

Las operaciones de renovación mediante la modernización de la oferta de alojamiento se constituyen en la actualidad como uno de los ejes de mayor importancia dentro de las múltiples estrategias de reestructuración para superar la situación de obsolescencia y pérdida de competitividad de destinos turísticos en fase de declive. Por ello, este documento centrará su análisis en el proceso de renovación edificatoria del sector de alojamiento de Puerto de la Cruz (Tenerife), un destino consolidado de los años 60 que arrastra históricamente un proceso paulatino de pérdida de competitividad. Los resultados obtenidos, revelan que, existe un importante déficit de renovación, orientándose las reformas hacia la conservación y mantenimiento de las edificaciones con un carácter más paliativo, que por la propia intencionalidad empresarial de mejorar. De este modo, resulta relevante exponer el proceso y las razones más importantes que explican este significativo fracaso.

Palabras clave: renovación hotelera; obsolescencia; reformas; Puerto de la Cruz; destinos consolidados.

Recibido: 9 de junio de 2015

Devuelto para su revisión: 3 de noviembre de 2015

Aceptado: 21 de diciembre de 2015

Departamento de Geografía. Universidad de La Laguna. Grupo ReinvenTUR: renovación e innovación turística E-mail:agustin.drguez@gmail.com

1 Este trabajo se enmarca en el proyecto de I+D+i denominado «Reinventur: Evaluación del impacto de las políticas públicas de renovación de destinos turísticos maduros. El caso de las Directrices de Ordenación del Turismo de Canarias» (SolSubC200801000279) financiado por la Agencia Canaria de Investigación, Innovación y Sociedad de la Información del Gobierno de Canarias y el Fondo Europeo de Desarrollo Regional (FEDER). 


\title{
The case of Puerto de la Cruz: the renewal of the offer of tourist accommodation destinations consolidated process
}

\begin{abstract}
Renewal operations by modernizing the offer of accommodation is now constitute one of the major axes within the multiple restructuring strategies to overcome the situation of obsolescence and loss of competitiveness of tourist destinations in decline phase. Therefore, this paper will focus its analysis on the renewal process edificatoria accommodation Puerto de la Cruz (Tenerife), a bound of the 60 target historically drags a gradual process of loss of competitiveness sector. The results reveal that there is a serious shortage of renewal, reform oriented towards the upkeep and maintenance of buildings with a more palliative than by the intent of improving business itself. Thus, it is relevant to explain the process and the most important reasons for this significant failure.
\end{abstract}

Keywords: hotel renovation; obsolescence; reforms; Puerto de la Cruz; consolidated destinations.

\section{INTRODUCCIÓN}

El fenómeno de la obsolescencia como problema en gran parte de los destinos turísticos del litoral catalogados como «maduros», «estancados» o «consolidados», -en función de la terminología utilizada por las diferentes teorías sobre el ciclo de vida de los destinos existentes dentro de la literatura turística-, se está extendiendo de forma generalizada en los últimos años por toda la geografía mundial. Su propio desarrollo y evolución turística han contribuido -en la mayoría de los casos-, a convertirse en destinos que se encuentran en una fase previa al declive, por lo que en muchas de estas situaciones, se han intentando definir distintas fórmulas para reinvertir esta situación y adaptarse de esta forma a los nuevos escenarios turísticos dentro de lo que se denomina modelo postfordista o neofordistas de acuerdo con Santos y Fernández (2010) o Vera Rebollo et al. (2011).

La apreciación sobre las opciones posibles de los destinos acerca de la fase de madurez, declive o el rejuvenecimiento siguen siendo las más frecuentes y las que gozan de mayor consideración en la literatura científica en esta materia (Martín Azami, 2005). Aún así, se reconoce la dificultad en la literatura al uso para poder definir claramente las distintas fases de evolución de los espacios turísticos consolidados (Parra, Melchior y Fuentes, 2010), por cuanto la duración y evolución del modelo tradicional del ciclo vital, no se puede predeterminar como una «ciencia exacta», estando sujeta a una enorme variabilidad y versatilidad, en función de numerosos factores o complejas relaciones de fuerza internas y externas que intervienen en el mismo (Agarwall, 2006), y que de una forma u otra, puede alterar este hipotético sistema de evolución turística clásico.

$\mathrm{Si}$ bien se reconocen infinidad de factores que influyen en el ciclo de vida de los destinos turísticos, este artículo se centrará en el importante papel que desempeña los alojamientos turísticos en el sistema turístico. 


\subsection{Revisión de la literatura en materia de renovación de la oferta de alojamiento turístico}

Las referencias académicas sobre la renovación edificatoria (física/funcional) vienen consolidándose desde mediados de la década de los 80 a partir de la necesidad de contrarrestar la pérdida de competitividad de muchos destinos turísticos consolidados con una oferta de alojamiento con necesidades de adaptación y modernización a la demanda turística. La literatura turística reconoce en la renovación de la oferta de alojamiento una parte clave dentro de las diversas estrategias de reestructuración para los destinos maduros con perspectivas de mejora. En la práctica, esta adaptación de los destinos consolidados a un modelo obsoleto depende, en gran parte, de la puesta en marcha de nuevas formas de gestión y planificación turística, así como de la implementación de ciertos elementos de atracción que estimulen y den respuestas a las múltiples y variadas formas de entender el turismo del siglo XXI ante la necesidad de «reinventar» estos destinos (Vera et al., 2011) ante las versátiles tendencias de consumo.

Para ello, los establecimientos turísticos se consideran como elementos estructurales del espacio producido del urbanismo del siglo XX (McNeill, 2008) y fundamentales como parte de las estrategias de renovación urbana. Podemos determinar, que los hoteles son uno de los grandes activos en el destino turístico y, por tanto, la importancia de corregir los problemas de deterioro u obsolescencia, derivados de los desajustes estructurales de los propios destinos turísticos con el transcurrir de los años o por la falta de control durante las fases de expansión de la misma (Antón, 2012), suponen un deber inexcusable para afrontar los nuevos retos de esta nueva era turística. De esta forma, la renovación de los establecimientos se erige como una de las tres generaciones de estrategias multisectoriales dentro de los procesos de transformación de los destinos a escala local. Según Antón (2012), ésta aporta complejidad e innovación y asimismo, supone una estrategia de reestructuración (Anton, 1997; Santos y Fernández, 2010; Vera et al., 2011) de los destinos turísticos consolidados en situación de declive, obsolescencia o pérdida de competitividad turística (Vera et al., 2011). Del mismo modo, se revela como una estrategia clave de cualquier política de reposicionamiento competitivo de acuerdo con Dorta, Simancas y García (2011) o de reconversión con el fin de recuperar su competitividad y reposicionarlos en los mercados turísticos (Simancas, 2010).

Desde el punto de vista teórico, la estrategia de renovación edificatoria de los destinos turísticos consolidados ha venido fundamentalmente desarrollándose en el marco de la teoría del ciclo de vida (Butler, 1980) así como en sus adaptaciones o revisiones más importantes que han contribuido a enriquecer el debate conceptual sobre la distintas formas de evolución teóricas de los destinos turísticos y a incidir en las diferentes formas de extensión del ciclo como parte de las estrategias de «rejuvenecimiento» de estos destinos en masa (Priestley y Mundet 1998; Johnston 2001; Agarwal, 2002 y 2006; Butler, 2006 a y b). También dentro de los denominados procesos de reestructuración hotelera en los que han incidido en la última década autores como: Anton (2011), Clegg y Essex (2000), Agarwal (2002), Vera y Baños (2010), Santos y Fernández (2010), Simancas (2011), Duro (2012), González Reverté (2012) o López y Ferreres (2011). Para ellos, la renovación de los establecimientos alojativos se ha planteado como una estrategia estructural para los procesos de modernización de los mismos y como parte del proceso de mejora de la competitividad y calidad de los destinos turísticos. 
Los establecimientos turísticos se conciben como verdaderos «activos» de los destinos y como parte de este potencial turístico, la renovación de la oferta turística desempeña un rol muy importante desde una doble vertiente: tanto por prevenir o superar la obsolescencia, el deterioro o la «mala» imagen de las edificaciones turísticas que puede representan una pérdida de calidad turística al destino (incluyendo procesos de demolición y esponjamiento o reconversión), como para incrementar los niveles de excelencia y calidad turística de los destinos incidiendo en la cualificación de la oferta.

$\mathrm{Si}$ bien es cierto que, por lo general, las referencias académicas disponibles no se centran específicamente en la renovación edificatoria como objetivo principal de las investigaciones, por cuanto abordan un espectro de mayor amplitud, se reconoce en gran parte de las mismas, el potencial de este tipo de estrategia como parte de los procesos de transformación de muchos destinos acusados por este fenómeno. Así, a lo largo de esta última década, las menciones a los procesos de renovación edificatoria han sido objeto de cuantiosas referencias académicas, entre las que destacamos: Anton (2004), Archer (1995), Donaire y Mundet (2001), Agarwal (2002), Potter y Phillips (2004), González et al., (2006), Chinchilla (2009), García Cruz (2013), Vera, Rodríguez y Capdepón (2010), Santos y Fernández (2010), Fuster et. al. (2010), Simancas (2010, 2011 y 2012), Obiol y Ferrandis (2012), Dorta (2010, 2011, 2013 y 2015), Dorta, Simancas y García (2011), Ivars, Rodríguez y Vera (2013). Estos autores, han corroborado la idea de que esta estrategia contribuye a la mejora de la renovación de las propias áreas turísticas, demostrando su incidencia y capacidad de transformación para destinos turísticos consolidados a escala local.

Esta situación se ha ido consolidando en el tiempo, sobre todo en la última década, a la par de un mayor interés en el estudio de esta materia por parte de disciplinas científicas como la Geografía del Turismo y otras ciencias afines, fortaleciendo líneas de trabajo y desarrollando proyectos de investigación tanto a escala regional como nacional sobre destinos turísticos maduros del litoral. Entre ellos, los proyectos financiados por el Plan Nacional de Investigación Científica y Desarrollo Tecnológico. Ministerio de Ciencia e Innovación (MICINN) y la conformación paulatina de grupos de investigación consolidados como los de Sostenibilidad y Territorio (GIST) de la Universidad de les Illes Balears, Análisis Territorial y Estudios Turísticos (GRATET) de la Universidad Rovira i Virgili de Tarragona, Instituto Universitario de Turismo y Desarrollo Económico Sostenible Tides de la Universidad de Las Palmas de Gran Canaria, Instituto Universitario de Investigaciones turísticas de la Universidad de Alicante o ReinvenTUR de la Universidad de La Laguna; éstos, se han convertido en verdaderos referentes en el campo de la renovación en el territorio nacional, generado un volumen de producción científica muy notable dentro de esta línea de investigación.

Desde esta perspectiva, este documento se centrará en el análisis del proceso de renovación edificatoria del sector de alojamiento de Puerto de la Cruz (Tenerife), como uno de los elementos claves en los modelos para la competitividad de los destinos en situación de estancamiento (Claver, Molina y Pereira, 2007). Un destino pionero y con experiencia de los años 60 que se encuentra en la actualidad en una fase de declive y con la incesante necesidad de articular medidas para su renovación. En este sentido, las operaciones de renovación mediante la modernización de la oferta de alojamiento se 
constituye como uno de los ejes de mayor importancia dentro de las múltiples estrategias de reestructuración para superar la situación de obsolescencia y pérdida de competitividad. Por ello, el destino turístico Puerto de la Cruz se convierte en un inmejorable ámbito territorial de experimentación de estos procesos desde el punto de vista de la Geografía del Turismo.

\section{EL PUERTO DE LA CRUZ COMO ÁREA TURÍSTICA EN FASE DE DECLIVE}

\subsection{Contexto territorial del área turística}

Puerto de la Cruz es un área turística de menos de diez kilómetros cuadrados localizada en el norte de Tenerife dentro Valle de la Orotava, siendo el municipio más pequeño de la comunidad Autónoma de Canarias (mapa 1). Alberga una población de 28.929 habitantes (INE, 2013) poseyendo un entramado urbano muy complejo, donde coexiste la actividad turística con la residencial derivada de su evolución histórica como ciudad (González y Hernández, 2010).

\section{Mapa 1 \\ LOCALIZACIÓN DEL DESTINO TURÍSTICO PUERTO DE LA CRUZ (TENERIFE, ESPAÑA)}

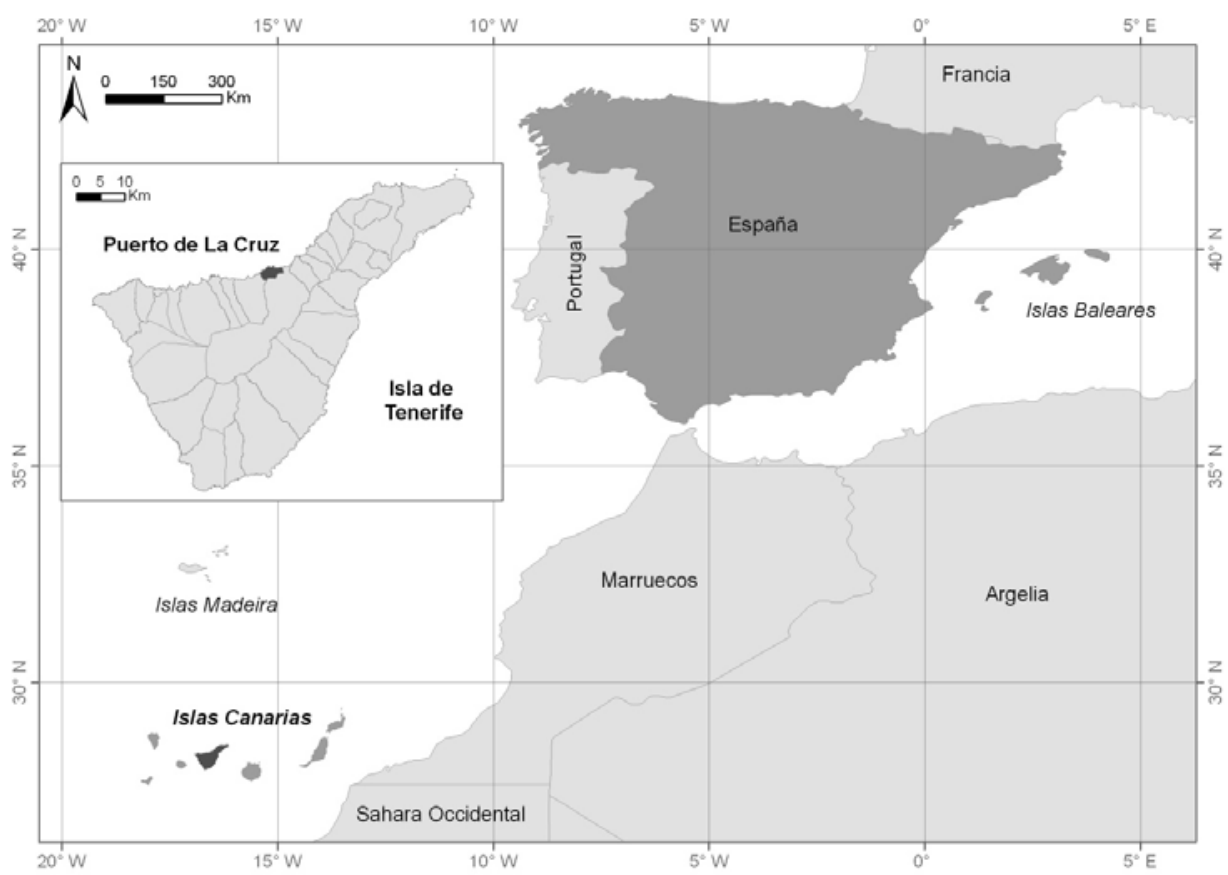

Fuente: elaboración propia. Software libre http://www.diva-gis.org/Datacountry boundaries 


\subsection{Algunas cifras turísticas sobre la oferta de alojamiento turístico de Puerto de la Cruz}

Atendiendo a los principales resultados derivados de la realización del Plan para la rehabilitación de las infraestructuras turísticas de Puerto de la Cruz (2011), (en adelante PRIT), señalamos los puntos de mayor relevancia:

- El destino puede considerarse como un destino complejo, con densidades y tipologías hoteleras muy diversas, con áreas muy diferenciadas en cuanto a distribución de activos y de recursos turísticos, tanto los tangibles como los intangibles.

- Desde el punto de las plazas turísticas, se estima que haya 22.721 según las fuentes oficiales disponibles (TURIDATA y Policía Turística). No obstante, en 2013 se identifican en explotación turística 19.829 plazas. A las plazas en explotación se suman otras 317 plazas que están en explotación sin licencia. Con lo cual se contabilizan 20.398 plazas en explotación y unos 96 establecimientos de alojamiento turístico, aunque la actividad turística se mantiene en 75 de ellas.

- Tres cuartas partes de la oferta de alojamiento turístico tienen una antigüedad de más de 30 años en el mercado, consecuencia del fuerte desarrollo de la oferta en el período 1962-1972 donde se construye gran parte de las plazas disponibles, por lo que se trata de una oferta «vieja» desde el punto de vista de la edificación (gráfico 1).

\section{Gráfico 1 \\ DISTRIBUCIÓN DEL NÚMERO DE PLAZAS SEGÚN AÑO DE EDIFICACIÓN}

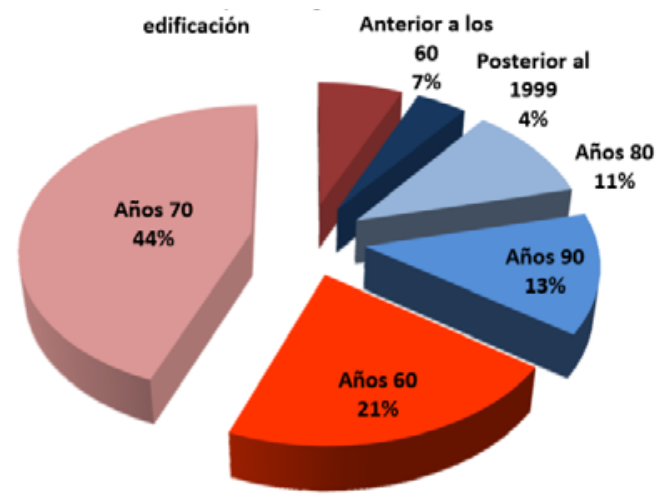

Fuente: PRIT (2011).

- En el caso de la categoría, buena parte de la oferta hotelera y extrahotelera se encuentran o superan las 3 llaves y 4 estrellas, además de albergar dos establecimientos de 5 estrellas, uno de ellos, con la distinción de gran lujo (gráfico 2). 


\section{Gráfico 2 \\ DISTRIBUCIÓN DE ALOJAMIENTOS TURÍSTICOS POR CATEGORÍA HOTELERA Y EXTRAHOTELERA}
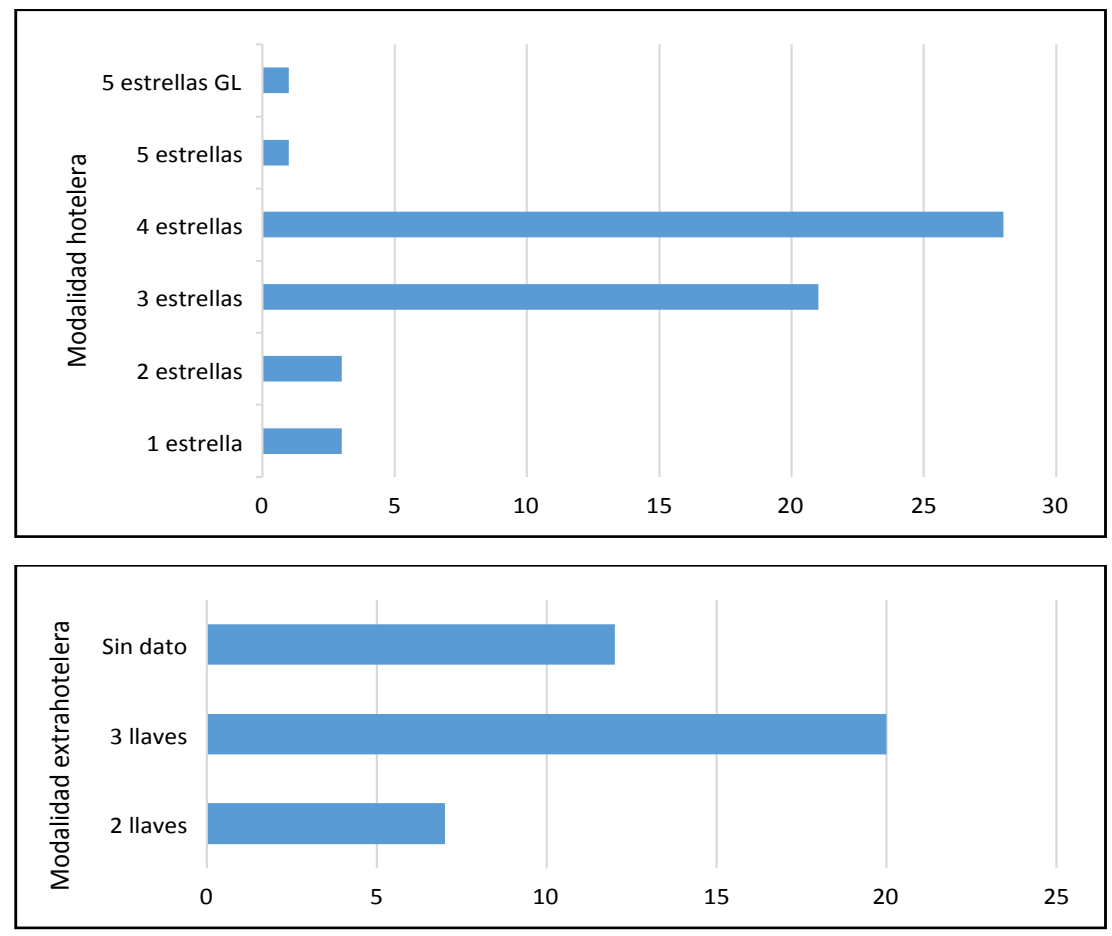

Fuente: PRIT (2011). Elaboración propia.

- Se ha identificado en el destino 1.063 plazas que, estando residencializadas, aún ostentan licencia de alojamiento, por lo que se requiere de su regularización.

- En relación con la gestión de los establecimientos cabe señalar el importante desarrollo de las cadenas hoteleras, ocasionando que el mercado turístico de Puerto de la Cruz haya pasado a depender en mayor medida de estas cadenas. No obstante, la situación actual es dual. Así, mientras que los establecimientos independientes predominan en número (el 52\%), no sucede lo mismo en relación con las plazas, en la medida en que los alojamientos asociados a cadenas controlan el 48,5\% de las mismas; esta circunstancia se deriva, entre otras razones, de la mayor capacidad media de los establecimientos (376 plazas de las cadenas frente 224 de los alojamientos independientes).

De hecho, la única excepción son los cuatro grupos empresariales locales, así como algunos casos hoteles que, aunque se gestionan por sus mismos propietarios, se han integrado para compartir ciertas decisiones de compra, producción, financiación, gestión y comercialización en busca de economías de escala (gráfico 3). 


\section{Gráfico 3 \\ FORMAS DE EXPLOTACIÓN \\ DE LA OFERTA TURÍSTICA DE PUERTO DE LA CRUZ}
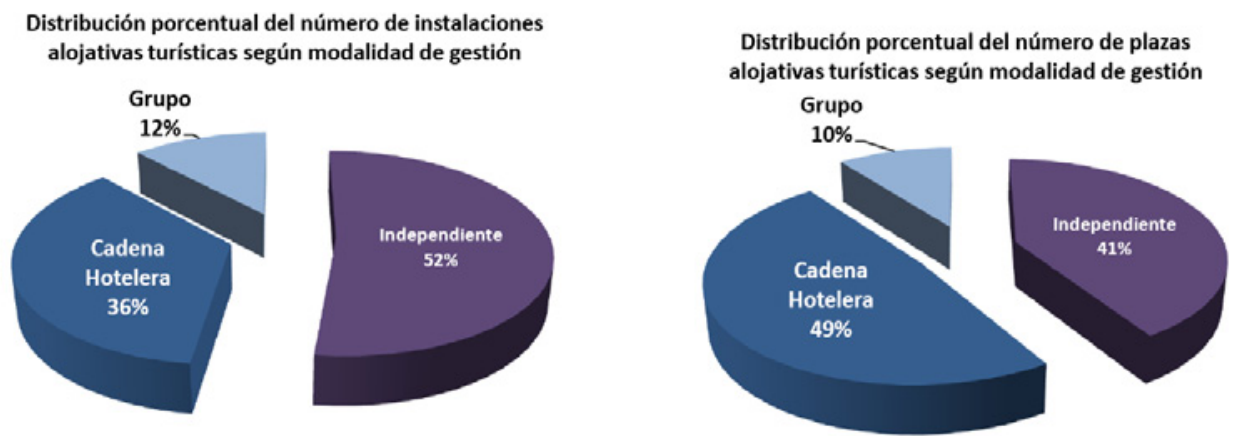

Fuente: PRIT (2011).

- En relación con la calidad hotelera, los alojamientos turísticos en ambas modalidades presentan un bajo nivel de certificación de reconocido prestigio. Así, los escasos establecimientos que han optado por certificarse lo han hecho en la ISO 14001 y la «Q» de la calidad turística. Unos datos bastante pobres si tenemos en cuenta que el destino, actuó como ciudad pionera en el proyecto piloto de implantación de los Planes de excelencia y calidad hotelera durante los años 90 (gráfico 4).

\section{Gráfico 4 \\ GRADO DE CERTIFICACIÓN DE LA CALIDAD \\ POR MODALIDAD ALOJATIVA}

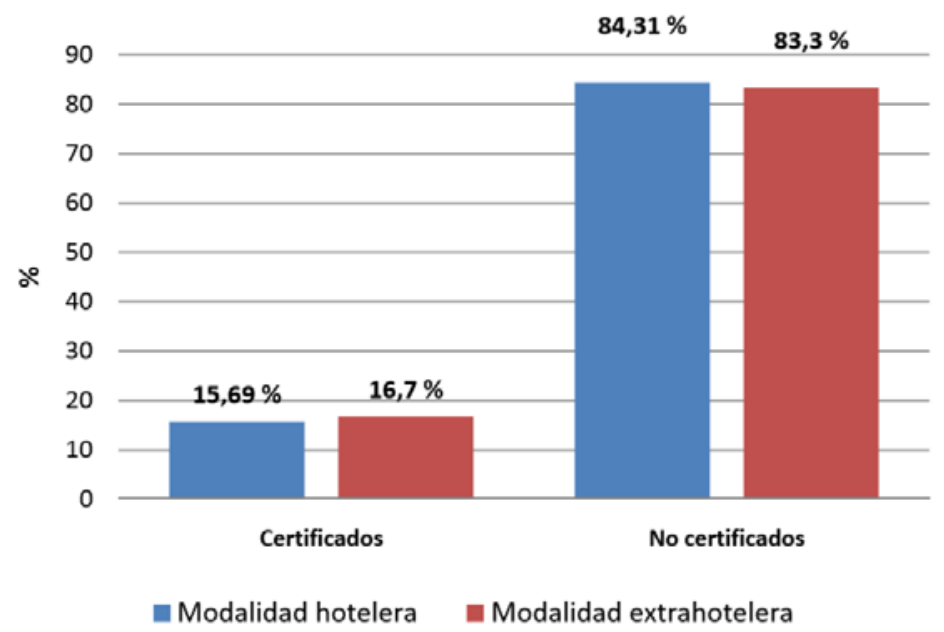

Fuente: PRIT (2011). 
- El destino presenta una importante debilidad en cuanto a rentabilidad empresarial. Esta debilidad puede evidenciarse, para el caso del sector hotelero, a través del RevPAR por el Barómetro de Rentabilidad y el Empleo de los destinos turísticos españoles elaborado por Exceltur (tabla 1). La rentabilidad hotelera de los últimos años del destino, se sitúa muy por debajo de la existente en las islas y de los principales municipios vacacionales de España (EXCELTUR).

\section{Tabla 1 \\ RANKING DE DESTINOS VACACIONALES \\ DE CANARIAS EN BASE A INGRESOS POR HABITACIÓN DISPONIBLE EN HOTELES EN 2009-2011 (€)}

\begin{tabular}{lccc}
\hline \multicolumn{1}{c}{ Destinos vacacionales } & Hot. 5, 4, 3 estrellas & Hot. 4 estrellas* & Hot. 3 estrellas* \\
\hline & $\mathbf{( 2 0 0 9}-\mathbf{2 0 1 0}$ - 2011) & $\mathbf{( 2 0 0 9 - 2 0 1 0 ~ - ~ 2 0 1 1 )}$ & $\mathbf{( 2 0 0 9 - 2 0 1 0 ~ - ~ 2 0 1 1 )}$ \\
\hline S. Bartolomé Tirajana (GC) & $62,5-62,6-69,1$ & $68,5-69,1-74,6$ & $44,3-40,3-45,0$ \\
\hline Mogán (GC) & $55,1-54,9-58,3$ & $66,8-65,5-65,5$ & $39,2-38,4-46,0$ \\
\hline Adeje (TF) & $54,1-57,6-67,3$ & $49,7-53,3-61,7$ & $27-26,4-32,1$ \\
\hline Tías (FU) & $52,7-56,6-58,7$ & $55,1-60,0-62,6$ & - \\
\hline La Oliva (FU) & $50,7-50,7-64,1$ & $4,1-16,0-34,9$ & - \\
\hline Arona (TF) & $49,4-49,9-58,2$ & $54,4-54,9-64,2$ & $31,2-29,6-38,0$ \\
\hline Pájara (FU) & $45,5-48,4-54,8$ & $46-50,6-57,4$ & $43,5-40,2-44,2$ \\
\hline Yaiza (LZ) & $45,1-35,6-43,2$ & $41,4-32,8-39,6$ & $14,5-24,9-30,6$ \\
\hline Media Nacional & 45 & 48,9 & 35,9 \\
\hline Teguise (LZ) & $41,9-40,5-48,7$ & $42,7-39,4-47,2$ & - \\
\hline Puerto de la Cruz (TF) & $31,8-30,3-34,8$ & $33,3-31,8-36,5$ & $20,8-19,8-24,4$ \\
\hline
\end{tabular}

Fuente: EXCELTUR y Encuesta de Ocupación Hotelera (INE). Elaboración propia.

* Se presentan datos desglosados en aquellos municipios turísticos donde se dispone de información significativa de más de cinco hoteles de la categoría analizada.

- Puerto de la Cruz ocupa el puesto $11^{\circ}$ en empleo turístico total de los destinos vacacionales españoles, con un total de 5.568 empleados en el sector. El año 2011 ha experimentado un crecimiento del 2,3\%, mejorando estos datos en el último año.

- Los perfiles de turistas alojados en los establecimientos turísticos se diferencian a lo largo del año y según tipologías de alojamiento. Los españoles tienen un marcado comportamiento estacional, concentrándose en los meses de verano, mientras que alemanes y nórdicos tienen mayores niveles de afluencia durante el invierno. A su vez, el uso de hoteles de mayor categoría como fórmula de alojamiento es mayoritaria entre los alemanes, británicos y españoles, mientras 
que los nórdicos muestran una mayor predilección por el uso de apartamentos. El mercado canario constituye un apoyo para los alojamientos de Puerto de la Cruz oscilando entre el 2,3\% de enero y el 9,4\% de agosto de 2010.

- En referencia al gasto turístico, aunque el gasto en origen es menor, el gasto en destino es ligeramente mayor que la media insular, lo que demuestra la gran actividad de los turistas que viajan a Puerto de la Cruz, relacionado con las salidas y excursiones a otros puntos de la isla. No obstante, la ocupación media está por debajo del $70 \%$ y el destino no alcanza con regularidad el millón de visitantes cada año.

\subsection{La obsolescencia del destino a partir de la aplicación del CVDT}

De acuerdo con las cifras citadas con anterioridad y las diferentes teorías promulgadas del CVDT, los distintos autores que han tenido Puerto de la Cruz como objeto de estudio lo han situado en una fase de madurez (Montero y Oreja, 1996; Gutiérrez y Oreja, 1998; Martín Martín, 1998; Cáceres, 2001; Martín Azami, 2005; Álvarez Alonso, 2004), llegando, incluso, más recientemente, a ubicarlo en fases de postestancamiento, declive o decadencia (Ledesma, 2012; Pérez y Páez, 2014; Dorta, 2015). De hecho, en la abundante literatura sobre Puerto de la Cruz, el uso de calificativos usados para determinar este «estado final» del ciclo de vida del destino ha sido muy prolífica y fundamentalmente asociados con connotaciones negativas, especialmente a partir de mediados de los años 80, cuando el destino empieza a mostrar signos de agotamiento de su modelo turístico. Esta tendencia ha sido creciente, auméntandose esta crisis de «marca» en los últimos años convirtiéndolo en un destino «muerto», «acabado» «poco renovado», como algunas de las referencias más utilizadas en los medios de comunicación y divulgación oral y escrita (Dorta, 2015).

La conclusión general de esta pérdida de competitividad es manifiesta; la necesidad de renovación de Puerto de la Cruz. Podemos decir, que el área turística ha transcendido de la fase de la madurez hacia una etapa posterior del modelo, en este caso, crítica, por cuanto se sitúa -siguiendo el propio modelo de Butler- en una fase de declive y, por ende, bajo el principio o fenómeno de la obsolescencia. Una situación, donde el paulatino proceso de depreciación turística se ha puesto de manifiesto, especialmente en la prensa, internet (a través del análisis online de comunidades de viajeros como Booking y Tripadvisor) y desde los propios stakeholders locales de la ciudad turística; circunstancias que atienden a hechos concretos a partir de factores endógenos y externos (Johnston, 2001) que explican dicha transición.

Llegados a este punto, reconocemos que el destino Puerto de la Cruz se encuentra en una fase de decadencia y declive. Ante esta situación, la relevancia de este documento se fundamenta en la importancia de la renovación edificatoria de alojamiento turístico como principal objeto de análisis, considerando que, se trata de una de una estrategia clave para la posible modernización del destino. Por tanto, el análisis en profundidad del proceso de renovación de la oferta de alojamiento de Puerto de la Cruz, se reconoce como punto de partida y como base para establecer una relación coherente entre lo que ha ocurrido en el pasado y el estado actual de la edificación turística en el destino. 


\section{METODOLOGÍA}

\subsection{La licencia urbanística como fuente primaria de información}

Para tratar de forma específica el problema de investigación en torno a la renovación de los establecimientos de Puerto de la Cruz ha sido necesaria la recopilación de información proveniente de las licencias urbanísticas de renovación edificatoria de los establecimientos turísticos. Las licencias urbanísticas se han planteado como una de las fuentes de información claves de esta investigación, procediendo a su recopilación en la Gerencia de Urbanismo y en el Archivo Municipal del Ayuntamiento de Puerto de la Cruz. Éstas han resultado esenciales para el análisis y valoración del proceso de renovación de la oferta de alojamiento turístico.

Para ello, se logró la identificación de las licencias urbanísticas desde el año 1955 -y de manera ininterrumpida hasta la actualidad-consiguiendo analizar todo el histórico de renovación en materia turística. Una vez extraída la información primigenia en las resoluciones de las licencias, fue precisa la consulta de los expedientes de las licencias más relevantes para extraer datos de mayor grado de especificidad, como el presupuesto económico de las obras o el desglose pormenorizado de los tipos de reforma a realizar (tabla 2).

\section{Tabla 2 \\ RESUMEN DE DATOS ESTADÍSTICOS EXTRAÍDOS DEL ANÁLISIS DE LICENCIAS URBANÍSTICAS DE REFORMA DE LA OFERTA DE ALOJAMIENTO TURÍSTICO EN PUERTO DE LA CRUZ}

\begin{tabular}{lc}
\hline \multicolumn{1}{c}{ Acciones } & Datos específicos \\
\hline Período de estudio & $1955-2009$ \\
\hline Tiempo empleado de recogida de información & 7 meses \\
\hline $\mathrm{N}^{\circ}$ de Consultas aproximadas de licencias de obras & 13.100 \\
\hline Media aproximada de licencias por año & 250 \\
\hline $\mathrm{N}^{\circ}$ total de Licencias en establecimientos turísticos & 930 \\
\hline $\mathrm{N}^{\circ}$ total de Licencias en establecimientos hoteleros & 600 \\
\hline $\mathrm{N}^{\circ}$ total de Licencias en establecimientos extrahoteleros & 330 \\
\hline $\mathrm{N}^{\circ}$ total de licencias de oferta complementaria & 55 \\
\hline $\mathrm{N}^{\circ}$ de Consultas aproximadas de expedientes de obras & 600 \\
\hline
\end{tabular}

Fuente: Área de Urbanismo y Archivo municipal del Ayuntamiento de Puerto de la Cruz. Elaboración propia.

\subsubsection{Estructuración, vaciado de datos y tratamiento de la información}

Con posterioridad, se procedió a incorporar la información adicional derivada de la explotación y cruce de variables para su implementación en un SIG. Se tuvo que hacer frente a la consulta de todas las licencias de obras archivadas y disponibles desde el año 
1955 para extraer aquellas licencias correspondientes al sector turístico. De este modo, fueron seleccionadas aquellas referidas a los establecimientos hoteleros y los apartamentos turísticos. En cuanto al tratamiento de la información, se realizaron un número aproximado de 13.100 consultas de resoluciones de licencias en base a una media aproximada de 250 licencias anuales durante 53 años y el primer trimestre del último año de análisis (19552009). De las 13.100 consultas de licencias urbanísticas totales, finalmente para nuestra base de datos identificamos aproximadamente 1.000 registros relacionados con el sector turístico. Una vez obtenido este importante volumen de datos, se precisó un tratamiento sistemático de la información a través del siguiente proceso secuencial:

1) La clasificación de las licencias urbanísticas en función de su propia naturaleza y modalidad alojativa. Se desglosaron en dos grandes grupos a partir de la información que contábamos de base sobre la oferta de alojamiento turístico existente. De esta forma, se conformaron dos grupos de análisis en función de la modalidad alojativa, es decir, hotelero y extrahotelero.

2) Análisis, ordenación, revisión y tratamiento de las licencias urbanísticas otorgadas para cada una de las modalidades turísticas. El objetivo de este procedimiento fue corregir y, en su caso, añadir información a aquellas licencias que presentaban algún tipo de dato impreciso, incomprensible, dudoso o que simplemente carecía de información clave.

3) Elección de la muestra definitiva para la construcción de la clasificación de reformas; a este respecto, se buscaba alcanzar una clasificación puramente orientada a licencias de reforma de las edificaciones turísticas de Puerto de la Cruz. Así, se excluyeron las licencias correspondientes a la construcción de hoteles (figura 19) o apartamentos turísticos, la de legalización de reformas, las demoliciones de antiguos hoteles o licencias para efectuar cambios de uso turístico a régimen extrahotelero o residencial.

\subsubsection{La elaboración de una clasificación de reformas y las clases de licencias}

Finalmente se realizó el proceso de agrupamiento de las licencias urbanísticas y, por ende, a los propios tipos de reformas. Este resultó ser el de mayor tiempo de dedicación y esfuerzo. Ello fue consecuencia de la complejidad de identificar, agrupar y clasificar los tipos de reforma para relacionarlas, con posterioridad, con las distintas clases de licencias que proponíamos en este documento de investigación. Por esta razón, a los efectos prácticos, esta fase metodológica se puede considerar, como uno de los ejes fundamentales de la investigación. De este modo, la clasificación de reformas se ha articulado a partir de tres grandes bloques a modo de licencias urbanísticas que aglutinan todos los contenidos (tabla 3) sobre las reformas acometidas en las edificaciones turísticas del destino. Se ha intentado que la clasificación aglutinara todos los contenidos de las reformas desde una doble vertiente: desde el punto de vista de la naturaleza-contenidos de las mismas; y desde la concepción de su localización (habitaciones, espacios comunes, espacios libres, etc.). De esta manera, se ha intentado establecer una visión global y, a la vez, sistémica, del conjunto de operaciones de renovación en la oferta de alojamiento turístico. Por ello, se crearon 
diferentes grupos dentro de los grandes ejes estructurales de las licencias urbanísticas para desarrollar cada una de ellas sectorialmente pero interrelacionadas en función del análisis empleado en este trabajo. Al mismo tiempo, estas clases de licencias urbanísticas se comportan como un sistema jerarquizado, puesto que integran distintos grupos y subgrupos (y los mismos), a los diferentes tipos de reformas.

\section{Tabla 3 \\ EJES ESTRUCTURALES SOBRE LAS CLASES DE LICENCIAS URBANÍSTICAS UTILIZADAS PARA LA CLASIFICACIÓN DE REFORMAS}

\section{Clases de licencias}

E1. Licencias de Obras mayores

E2. Licencias de Obras menores

E3. Licencias de Actividades e Instalación

Fuente: elaboración propia.

De todo el proceso de elaboración, sistematización, explicación y desarrollo de las clases de licencias urbanísticas, se pudo establecer una clasificación de reformas estructural e integrada a modo de cuadro-resumen. Esta nos ha posibilitado el acceso de información de los contenidos de las reformas acontecidas en los establecimientos turísticos de Puerto de la Cruz donde se hace referencia a los tipos de reforma divididos por ubicación y sus características principales. Una parte ha sido incluida dentro de la categorización de obras mixtas o de varios elementos cuando la situación lo requería. A su vez, se extrajeron aquellas reformas que presentan «personalidad propia» para adquirir una categorización concreta.

\subsubsection{Diseño de la muestra y procesamiento}

En cuanto a la población de estudio, se tomó como referencia todos los establecimientos turísticos disponibles de Puerto de la Cruz a lo largo de su historia. Desde el punto de vista estadístico, se pudo recabar información de 90 establecimientos, aunque con posteridad, a través de la revisión que se efectuó con el PRIT (2011) se detectaron 12 alojamientos turísticos que se encontraban cerrados o/y «sin uso reconocido», 9 completamente destinados a uso residencial aunque figuraban como «turísticos» oficialmente, así como 10 que mantenían diferentes grados de uso mixto (turístico-residencial). Por esta razón, el análisis más exhaustivo se realizó a 75 instalaciones turísticas que conservaban totalmente su actividad turística.

La recogida de la información se realizó a través de la visita a los establecimientos turísticos durante un período de tres meses en el año 2008. La información recopilada fue revisada y actualizada durante los meses de mayo y agosto de 2011, mediante visitas presenciales, llamadas telefónicas, consultas al informe de la Policía Turística sobre la oferta de alojamiento de la ciudad, el listado de hoteles y apartamentos del Servicio de 
Información turístico de Puerto de la Cruz y a través de las páginas corporativas de las propias instalaciones. Asimismo, se llevó a cabo el proceso de entrevista con las diferentes personas encargadas de la difusión de la misma, bien del personal de recepción y directivos hoteleros en los establecimientos gestionados por cadenas hoteleras o grupos empresariales locales, y bien de los propios directores y propietarios de los de tipo independiente.

Una vez obtenida la información de los cuestionarios realizados en papel, se procedió a su revisión en profundidad, con el fin de validarlos. La codificación de los cuestionarios/establecimientos se hizo, teniendo en cuenta el diseño y la construcción de nuestra propia base de datos en el programa Excel, donde la información fue transcrita del papel al soporte informático. Tras la grabación de los datos, éstos fueron exportados a la base de datos que se había construido en el SIG donde finalmente se produjo el tratamiento de la información. Esta base de datos, se creó dentro del marco del Proyecto I+D+i ReinvenTUR por cuanto, este trabajo es uno de los resultados de investigación esperados de este proyecto, donde, además de recopilar numerosa información de la oferta de alojamiento turístico de Canarias, se había profundizado de una forma especial en la información de Puerto de la Cruz. Una base que se retroalimentó con posterioridad con la redacción del PRIT.

\section{RESULTADOS OBTENIDOS}

\subsection{El marco general de la renovación de la oferta de alojamiento turístico}

Los resultados obtenidos derivados de las licencias urbanísticas de reforma señalan que se extendieron por cauces legales 649 licencias de reforma. Esto revela un déficit importante en cuanto al número de reformas ejecutadas teniendo en cuenta el período de investigación (gráfico 5).

Así, en la oferta hotelera, la cuantía menor corresponde a la clase de reformas de actividades de instalación y cerramientos (14\%), seguido de las obras mayores, (un 20\%), y las licencias de obra menor, $(66 \%)$. En general, y atendiendo a las diferentes tipologías de reformas, podemos sistematizar el papel de la renovación en la oferta hotelera en dos aspectos:

1) Los proyectos de obra mayor en la oferta hotelera han sido minoritarios, basándose principalmente en reformas orientadas al cumplimiento de la normativa turística, en concreto, la relativa a la seguridad. Si bien han existido algunas actuaciones de renovación integral, que han resultado relevantes en el tiempo, prácticamente las intervenciones dentro de esta categoría no han incidido en los procesos de modernización de las edificaciones existentes.

2) El alto porcentaje de reformas de obra menor, así como las de acondicionamiento. Ello demuestra que las actuaciones se han dirigido básicamente al mantenimiento y conservación de las edificaciones turísticas. Este hecho, enfatiza el papel desinversor que se ha venido produciendo en los establecimientos turísticos a la par del deterioro y obsolescencia de los mismos con el paso de los años ante la escasa reinversión materializable (González, Padrón y León, 2006). 
La modalidad extrahotelera ha seguido la misma tónica, sobre todo, si se tiene en cuenta la antigüedad de este destino turístico. Las licencias se corresponden básicamente con actuaciones conservación y mantenimiento de las instalaciones, y, por tanto, a obras menores. Unos proyectos que se corresponden con un $71 \%$ del total de licencias frente al $11 \%$ de las licencias destinadas a acondicionar los apartamentos turísticos con servicios para mejorar su funcionamiento, a través de operaciones como la apertura de pozos absorbentes o las obras de cerramientos de los complejos.

\section{Gráfico 5 \\ DISTRIBUCIÓN PORCENTUAL POR CLASES DE LICENCIAS EN LA RENOVACIÓN DE LA OFERTA TURÍSTICA DE PUERTO DE LA CRUZ (1955-2009)}
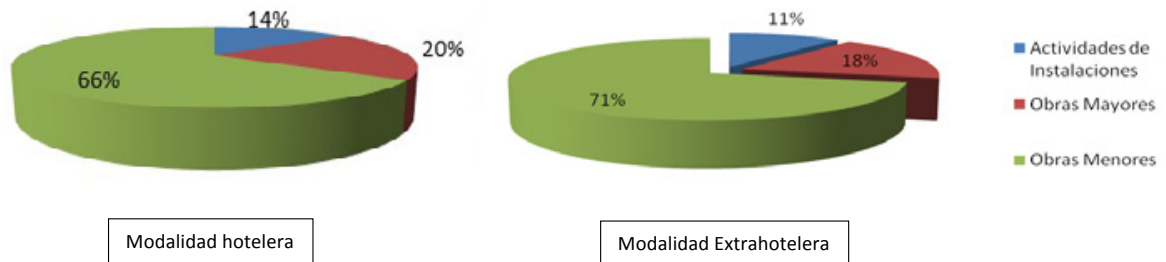

Modalidad hotelera

Modalidad Extrahotelera

Fuente: Gerencia de Urbanismo y Archivo municipal del Ayuntamiento de Puerto de la Cruz. Elaboración propia.

\subsection{El proceso de renovación de la oferta de alojamiento turístico}

\subsubsection{La fase de desarrollo y consolidación de la oferta turística de alojamiento (1955- 1979)}

Puerto de la Cruz experimentó a principios de los años 50, el proceso de consolidación con un verdadero desarrollismo urbano. Supuso un proceso de nueva organización territorial del litoral portuense que fue incentivado a partir de la declaración del Puerto de la Cruz como «Lugar de Interés Turístico» por orden del Ministerio de Información y Turismo (González Lemus y Hernández, 2010). Con este impulso, aparecen los primeros hoteles a finales de los años 50: el Hotel Bélgica en 1957, el Hotel Gran Tenerife Playa, -en la actualidad H10 Tenerife Playa-, el Hotel Las Vegas -en la actualidad Hotel Catalonia Las Vegas-, el Hotel Valle Mar, el Hotel Oro Negro inaugurado en el año 1959 con 84 camas o el Hotel Tigaiga. Este desarrollo continuó en la década de los años 60, donde se produce el gran boom turístico de Puerto de la Cruz. De hecho, el potencial de la zona de Martiánez (principal zona turística) en materia hotelera era realmente importante, teniendo en cuenta que para el año 1963 se contaba con una capacidad de 3.000 plazas y estaban proyectadas otras 4.000 a corto plazo (González Lemus y Hernández, 2010). Estas estimaciones fueron rebasadas con creces, multiplicándose el número de plazas turísticas durante esta etapa a un ritmo vertiginoso. Así, el número de turistas no dejó de incrementarse, lo que favoreció que el número de plazas turísticas ascendiera hasta las 10.802 en 1967 (Álvarez, 
2004). A pesar de ello, éstas resultaron insuficientes, para albergar la demanda turística del momento. Ello animó a empresarios y promotores del sector a seguir construyendo nuevos establecimientos turísticos para cubrir el déficit existente en relación al número de plazas que ofertaba el destino.

En este sentido, el proceso de renovación de la oferta hotelera y extrahotelera en estos años se asoció fundamentalmente al momento de expansión y bonanza del propio destino, por lo que las obras que se desarrollaron fueron básicamente de ampliación de las instalaciones, obras menores de acondicionamiento y la instalación/adecuación de servicios básicos para el buen funcionamiento de las mismas. Como se puede observar en la tabla 4, la tendencia positiva del número de licencias desde los años 60 hasta el comienzo de los años ochenta es bastante notable. En estas dos décadas, el incremento del número de licencias representa este proceso de crecimiento turístico de Puerto de la Cruz por lo que la escasez de licencias para el primer período, 77 licencias en 14 años, se explica teniendo en cuenta que es el momento de inicio y expansión de la oferta turística de la ciudad. Esta consideración se debe en parte a las primeras actuaciones de planes parciales y proyectos de urbanización de la ciudad, a partir de la aprobación del primer Plan General de Ordenación Urbana de Puerto de la Cruz de 1958 y otros proyectos de urbanización en el destino. El modelo alojativo elegido fue el hotelero, en detrimento del extrahotelero. En este contexto de fiebre constructiva del destino, se siguen multiplicando los proyectos de nueva construcción hotelera favorecida por las facilidades de la Administración Central en materia de créditos a largo plazo con un tipo de interés muy bajo (Ashotel, 1985) y con las garantías de amortización a corto y medio plazo en un sector donde apenas existía riesgo empresarial. Estas circunstancias favoreció la continuación del «ladrillo» y como consecuencia, la concesión de más licencias para la construcción de hoteles, apartamentos y residencias turísticas llegando a alcanzar solo en 1970, unas 7.379 camas turísticas tal y como señalan González Lemus y Hernández (2010), que ejemplifican la voraz actividad del sector.

Tabla 4

NÚMERO DE LICENCIAS URBANÍSTICAS DE REFORMA TURÍSTICA POR MODALIDAD Y PERÍODOS TEMPORALES EN LA FASE DE DESARROLLO Y CONSOLIDACIÓN DEL DESTINO

\begin{tabular}{ccccc}
\hline Períodos & $\begin{array}{c}\text { Licencias } \\
\text { hoteleras }\end{array}$ & $\begin{array}{c}\text { Licencias } \\
\text { extrahoteleras }\end{array}$ & Total Licencias & \% total \\
\hline $1955-59$ & 1 & 0 & 1 & 0,4 \\
\hline $1960-69$ & 63 & 14 & 77 & 28,4 \\
\hline $1970-79$ & 148 & 45 & 193 & 71,2 \\
\hline Total & $\mathbf{2 1 2}$ & $\mathbf{5 9}$ & $\mathbf{2 7 1}$ & 100 \\
\hline
\end{tabular}

Fuente: Gerencia de Urbanismo y Archivo municipal del Ayuntamiento de Puerto de la Cruz. Elaboración propia.

Desde esta perspectiva, la renovación de los establecimientos pasa por adaptarse a las expectativas del nuevo modelo de «turismo de masas». Estos cambios suponen transformaciones en algunas de las instalaciones, que motivadas por la buena dinámica del sector, 
proyectan nuevas intervenciones, con el objetivo de adecuarlas ante la nueva y creciente demanda turística. Ello explica que, algunas de estas operaciones consistieran en reformas orientadas a la ampliación de las instalaciones, con el fin de ampliar su capacidad alojativa a través de anexos edificatorios, acondicionamiento de nuevas zonas de esparcimiento, construcción de nuevas plantas, áticos, dependencias concretas, salones, etc.). También se acometieron obras menores de acondicionamiento y adecuación de servicios esenciales para las edificaciones, tales como obras de decoración y embellecimiento, reformas de los bajos de los hoteles, construcciones menores, aperturas de pozos absorbentes, etc. Esta casuística la encontramos en algunos casos a través de la concesión de licencias de. Así, en el proyecto de reforma del Hotel La Paz, se argumentó en su memoria descriptiva de la siguiente manera:

«Dada la aceptación que ha tenido la instalación del construido Hotel La Paz, de categoría cuatro estrellas y la gran demanda de nuevas plazas de alojamiento, los propietarios del referido Hotel han estimado conveniente la ampliación del mismo, consistente en la construcción de un edificio situado al otro lado de la carretera del Botánico...» (31 de octubre de 1970).

Este impulso quedó reflejado en la estructura territorial de Puerto de la Cruz durante esta década (1962-1972), donde se suceden numerosos proyectos urbanísticos a través de un urbanismo «depredador « sin precedentes, construyéndose casi 20.000 nuevas plazas de alojamiento, habiéndose superado las 30.000 plazas alojativas en vísperas de la crisis energética de 1973 (Álvarez, 2004). De hecho, uno de los proyectos singulares dentro de este boom urbanístico de la ciudad fue la construcción del Hotel Belair en 1963. Éste se proyectó inicialmente para tener 27 plantas y una altura de 70 metros, rompiendo totalmente el canon de construcción típico de la zona y estableciendo un nuevo modelo de «ciudad vertical», a modo de New York City, con grandes torres y edificaciones ligado al curso positivo de la economía. Este anteproyecto se materializó finalmente en una edificación algo más «moderada» en cuanto a sus dimensiones. Aun así, se convirtió en el edificio más alto de toda la isla de Tenerife, siendo ejemplo de modernidad del destino.

\subsubsection{La crisis del sector turístico del destino (1973-1979)}

Los primeros síntomas de agotamiento del modelo turístico de Puerto de la Cruz se reflejaron en una pérdida del número de instalaciones y plazas turísticas, especialmente las extrahoteleras, pues, durante el período 1972-1980 disminuyen 5.486 plazas turísticas, pasando de 13.377 en 1972 a 7.891 plazas en 1980 (Álvarez, 2004). Ello denota una «paralización» de la actividad constructiva de hoteles y apartamentos destinados al sector turístico; así, sólo se solicitan 8 licencias de nueva construcción, lo que contrasta con las 185 durante el período 1962-1972 (tabla 5).

Esta circunstancia nos confirma la idea de que la mayoría de estos apartamentos turísticos pasaron a convertirse a residenciales tal y como se reflejan en algunas licencias urbanísticas encontradas al efecto a mediados de los 70, donde se hace alusión explícitasobre este asunto. 
Tabla 5

EVOLUCIÓN DE LICENCIAS DE NUEVA CONSTRUCCIÓN (HOTELES Y APARTAMENTOS TURÍSTICOS) EN PUERTO DE LA CRUZ SEGÚN FASES DE DESARROLLO (1955-1989)

\begin{tabular}{lcc}
\hline \multicolumn{1}{c}{ Fases de desarrollo } & Licencias nueva construcción & \% Total \\
\hline Inicio actividad turística (1955-1961) & 13 & 5,6 \\
\hline Boom turístico-inmobiliario (1962-1972) & 185 & 79,4 \\
\hline Crisis Petróleo (1973-1979) & 8 & 3,4 \\
\hline Estabilización/ madurez (1980-1989) & 27 & 11,6 \\
\hline Total & $\mathbf{2 3 3}$ & $\mathbf{1 0 0}$ \\
\hline
\end{tabular}

Fuente: Elaboración propia según datos obtenidos de las Licencias urbanísticas de Ayto. Puerto de la Cruz para el período analizado.

Dentro de este contexto de crisis, la construcción de hoteles comenzó a resentirse, por su elevado coste económico y las escasas expectativas de beneficio a reinvertir ante tal inversión (Ashotel, 1985). Esta situación se reflejó en la pérdida del número de plazas extrahoteleras y la ralentización del número de nuevas plazas hoteleras como consecuencia de este «parón inmobiliario». Bajo estas circunstancias, el proceso de renovación de la infraestructura de alojamiento si bien no desciende en cuanto al número de licencias urbanísticas expedidas se refiere, si lo hace en cuanto a su funcionalidad, que difieren en su conjunto de las correspondientes a la «época dorada» de Puerto de la Cruz. Las intervenciones son, además, reflejo de una clara «desinversión» de capital, siendo, en su mayoría, de un menor «calado».

Así, el 70\% del conjunto de licencias se correspondieron con obras menores (si tenemos en cuenta la suma de obras menores y actividades e instalación) como se puede apreciar (gráfico 6) dirigidas fundamentalmente a la adecuación de las instalaciones a cambios en materia de salubridad y funcionalidad. De esta manera, se trata de reformas con carácter más paliativo, que por la propia intencionalidad empresarial de mejorar.

\section{Gráfico 6 \\ DISTRIBUCIÓN PORCENTUAL DE LICENCIAS URBANÍSTICAS POR CLASE DENTRO DE LA OFERTA TURÍSTICA EN EL PERÍODO DE CRISIS DEL SECTOR EN EL DESTINO (1973-1979)}

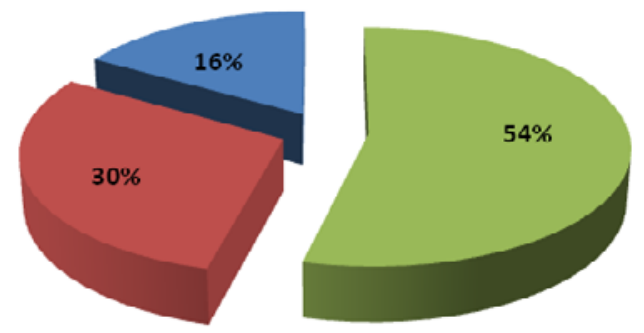

= Obras menores
@ Obras mayores

Actividades e Instalación

Fuente: Gerencia de Urbanismo y Archivo municipal del Ayuntamiento de Puerto de la Cruz. Elaboración propia. 
Sin lugar a dudas, se trató de un período de recesión económica, que se tradujo en obras que fueron prácticamente de mantenimiento o de conservación, siguiendo la línea paliativa de las edificaciones. Ello repercutió en un mayor control sobre la inversión en la oferta de alojamiento en materia de renovación ante la escasa perspectiva de poder reinvertir en corto plazo el capital invertido.

\subsection{La fase de obsolescencia de la oferta de alojamiento turístico (1980-1999)}

\subsubsection{El estancamiento del destino turístico}

Puerto de la Cruz experimentó en los primeros años de la década de los 80 , las consecuencias y factores negativos que arrastraba del pasado, reflejando que el destino turístico no pasaba por sus mejores momentos. Esta situación de crisis se agravó con el desarrollo acelerado de la actividad turística en el sur de la isla de Tenerife. Así, Puerto de la Cruz empezó a experimentar de forma directa los efectos de ese nuevo modelo de desarrollo territorial insular al que no sabe responder. La contradicción se plantea en la medida en que el modelo turístico de «sol y playa», aplicado en el municipio a lo largo de 30 años, no era el más adecuado, dado que el número de horas de sol anuales era muy inferior a la zona sur de la isla, así como por las escasas condiciones naturales para la práctica del baño. Así, con respecto a la producción de nuevos espacios turísticos como Arona y Adeje en el sur de la isla de Tenerife, el destino queda estancado en el tiempo con 784.169 turistas en 1985, solo 62 turistas más que para el año 1978.

\subsubsection{La conservación y mantenimiento de los establecimientos turísticos como estrategia de renovación}

Si bien los primeros años de la década de los años 80 dejan «buenas sensaciones» en función al número de licencias ejecutadas en los establecimientos turísticos de la ciudad; no obstante, éstas no supusieron en esencia, una mejora general de la oferta turística, salvo algunas instalaciones que materializaron determinadas obras de interés. En relación con las licencias de obra mayor, éstas representan un bajo porcentaje durante este período. Asimismo, destacan la adaptación de las instalaciones turísticas a los sistemas de seguridad y emergencia. Ello se debió a la necesidad preventiva de adecuarse a las regulaciones específicas sobre seguridad contra incendios fijadas por la Ley de Prevención de Incendios en Establecimientos Turísticos publicada en el BOE el 2 de octubre de 1979. Esta obligación fue un problema «técnico» e incluso estructural para el destino Puerto de la Cruz, pues, prácticamente la totalidad de la infraestructura turística se había construido de modo que muchas de ellas presentaban ciertas debilidades en cuanto a la seguridad contra incendios (señalización, evacuación, alarmas, alumbrado, etc.). Aún así, se hicieron mejoras sustanciales de la imagen de algunos establecimientos de la ciudad, como en los hoteles Las Águilas, Valle Mar y el Tigaiga, donde se ejecutan las obras de mayor consideración teniendo en cuenta su rentabilidad.

A la par de este proceso de pérdida de competitividad del destino, los establecimientos hoteleros fueron perdiendo capacidad de ocupación como consecuencia del importante 
descenso de turistas. De acuerdo con González Lemus et al. (2005), esta situación fue más fuerte durante el período 1989-1994, donde el destino pasó por una extrema debilidad comercial y el mercado británico desapareció casi por completo tras su progresiva desviación por parte de los turoperadores hacia el sur de Tenerife (Dorta, Simancas y García, 2011). Como indica Álvarez (2004:131), se trató de «uno de los episodios más críticos de esta crisis en el desarrollo turístico del destino turístico».

El destino -y su modelo turístico- quedó enclavado en una crisis estructural, que afectó prácticamente toda la infraestructura de alojamiento turístico que se había quedado obsoleta en pocos años. Como observamos en el gráfico 7, el déficit de renovación se percibe claramente teniendo en cuenta el descenso de licencias ejecutadas con respecto al período anterior.

\section{Gráfico 7}

\section{COMPARACIÓN DE NÚMERO DE LICENCIAS DE REFORMA POR} MODALIDAD DE ALOJAMIENTO POR PERÍODOS TEMPORALES

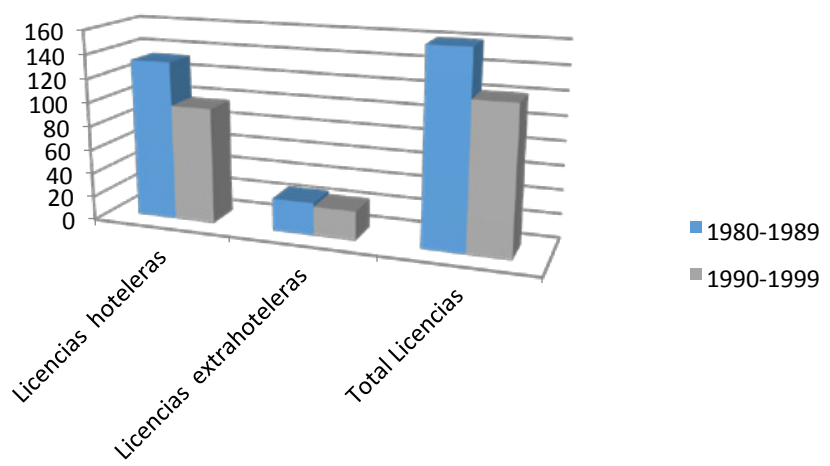

Fuente: Gerencia de Urbanismo y Archivo municipal del Ayuntamiento de Puerto de la Cruz. Elaboración propia.

Desde este punto de vista, en estos primeros años de la década de los 90 hay un escaso movimiento en cuanto a reformas. Así, los resultados señalan la ausencia de obras mayores, salvo las concernientes a cumplir con la normativa vigente en materia de prevención y protección contra incendios. De resto se tratan de obras de poco calado como el acondicionamiento de los bajos de los hoteles (reposicionamiento de pavimentos, carpintería, revestido interior, pintura), reformas orientadas a cuestiones técnicas y de seguridad, como la reparación e impermeabilización de las cubiertas de varios hoteles y algunas, incidiendo en un remozamiento general de las instalaciones. Una situación que bien se refleja en el Hotel Atlantis Playa que en su memoria descriptiva, contextualiza perfectamente el momento por el que pasa el sector hotelero de la ciudad.

"Que el momento en que se encuentra el sector turístico, supone un momento crítico, en el que necesariamente obliga a su representada, aun careciendo de medios propios para ello, a realizar una reforma de las zonas nobles del Hotel Atlantis 
Playa de esta ciudad, a fin de dar al hotel un nuevo estilo, más moderno, menos clásico y rehacer dichas zonas para que presenten un verdadero estado de nuevas» (Exposición de motivos para la solicitud de licencia. H. Atlantis Playa, 1992).

\subsubsection{El Plan de calidad hotelera como reactivo de la renovación}

El Plan de Calidad hotelera (1994) fue el primer proyecto piloto apoyado por el Plan Futures con el objetivo de abordar acciones estratégicas capaces de reinvertir la situación de obsolescencia de los establecimientos hoteleros para buscar la renovación global del destino a partir de la gestión de la calidad. En Puerto de la Cruz la iniciativa fue respaldada por 25 establecimientos y uno de los objetivos fue la implantación de una marca de calidad para recuperar la competitividad perdida en antaño. La propuesta se basó en una serie de estándares de calidad que los propios empresarios hoteleros se impusieron como parte de la estrategia de obtener una mayor excelencia, prestando un mejor servicio a los clientes. Para ello, los hoteles tuvieron que adecuarse desarrollando diferentes operaciones de renovación para cumplir con dichos estándares. Ello explica, que durante estos años se aprecie un mayor número de licencias de obras de reforma autorizadas en el destino. Estos planes implementados durante los años 90 tuvieron un efecto «reactivo» en la modernización de la oferta turística. Este hecho queda evidenciado en el incremento del número de licencias con respecto a los años anteriores, siendo bastante ostensible en los años 1996 y 1997, fechas en las se realizan importantes intervenciones que inciden en una mejora de la calidad turística de la oferta (gráfico 8).

\section{Gráfico 8 \\ EVOLUCIÓN DEL NÚMERO DE LICENCIAS POR MODALIDAD ALOJATIVA (1973-1999)}

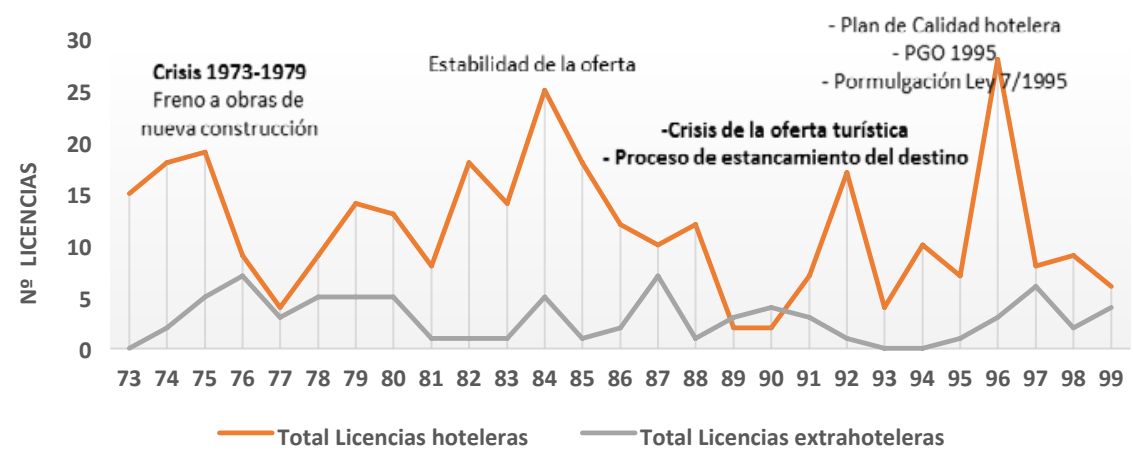

Fuente: Gerencia de Urbanismo y Archivo municipal del Ayuntamiento de Puerto de la Cruz. Elaboración propia.

Si bien estas reformas de obra menor no dejan de ser puntuales para gran parte de los hoteles y apartamentos, si es cierto que su puesta en marcha supuso más que una simple operación de remozamiento, demostrando al menos un cambio de mentalidad desde el punto de vista empresarial. No obstante, el destino turístico inserto en medio de una crisis de llegada de turistas y una masificación del destino con 30.000 plazas hoteleras, no supo 
consensuar la coordinación necesaria entre los distintos agentes y actores del escenario turístico para favorecer políticas de inversión de capital en la renovación de la oferta existente en el Puerto de la Cruz. Ello provocó que el proceso de deterioro del grueso de edificaciones de alojamiento turístico siguiera avanzando a la par de la propia depreciación del destino. Una situación que explica las escasas garantías de éxito para una verdadera renovación en el sector turístico (González, León y Padrón, 2006).

\subsection{La fase de declive de la oferta de alojamiento turístico (2000-2009)}

La etapa de desarrollo turístico de Puerto de la Cruz durante los años 2000 va a estar marcada por numerosos cambios legislativos en materia turística en Canarias y una enorme inestabilidad política a escala local. El sector turístico hotelero de Puerto de la Cruz se encuentra en un momento crítico, existiendo una bipolaridad en cuanto al proceso de renovación se refiere. Por un lado, aquellas intervenciones que continuan la estrategia vía obsolescencia y por otro, las que concretan en algunos establecimientos que demuestran «sobrevivir» a la profunda y extendida crisis de identidad del área turística. Por tanto esta etapa se dividirá en dos fases.

\subsubsection{La renovación parcial de la oferta de alojamiento (2000-2002)}

El número de licencias de obras otorgadas para estos primeros años de siglo presentó ciertos atisbos de esperanza desde el punto de la renovación. Si bien el conjunto de reformas desarrolladas durante estos primeros años siguen enfocadas a la estricta conservación y mantenimiento de las edificaciones, los resultados demostraban una fuerte actividad para el período 2000-2002, existiendo en algunas intervenciones, un atisbo de «renovación integral» como le ocurriera al Hotel Orotava Palace. En definitiva, representaba la necesidad urgente por parte de los empresarios hoteleros en adecuarse a la estructura del mercado turístico como parte de la estrategia de supervivencia del sector. Este tipo de renovación se contextualizó dentro de los parámetros de «tiempo límite», es decir, en un momento de agotamiento del ciclo de vida útil de la edificación y con la incapacidad por

\section{Gráfico 9 \\ PESO PORCENTUAL DE LICENCIAS DE REFORMA TOTALES OTORGADAS POR PERÍODOS (2000-2009)}

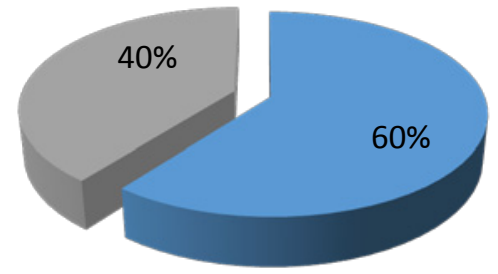

- 2000-2002

2003-2009

Fuente: Gerencia de Urbanismo y Archivo municipal del Ayuntamiento de Puerto de la Cruz. Elaboración propia. 
parte de la propiedad para mantener en activo y en cuotas de rentabilidad, lo que supone la estrategia de renovación vía obsolescencia (González, León y Padrón, 2006). Es por ello, por lo que se materializaron gran parte de los proyectos de reforma de la década con un $60 \%$ del total (gráfico 9), incluso con la construcción de nueva planta hotelera con el Hotel Diamante Suites de categoría de cuatro estrellas.

\subsubsection{La consolidación de la decadencia en la oferta de alojamiento turístico (2003-2009)}

Si bien pareció que había existido un pequeño signo de recuperación, a partir del año 2003, podemos decir que se produce un total estancamiento del proceso de renovación de la oferta alojativa turística de Puerto de la Cruz. Estamos en un contexto temporal donde se articulan numerosas iniciativas en forma de planes y proyectos dirigidos a recuperar el atractivo turístico, pero sin llegar a implementar estrategias reactivas capaces de responder al proceso de declive. Además, este período estará marcado fundamentalmente por una concatenación de factores de tipo interno y externo, que marcarán el devenir de Puerto de la Cruz y el de la propia infraestructura de alojamiento turístico. Estos se convierten en fundamentales para entender el fracaso de la renovación en el destino. Entre ellos podemos señalar las siguientes:

- La falta de articulación de un modelo turístico claramente definido para el destino turístico y una estrategia clara para reinvertir el proceso de obsolescencia de la oferta de alojamiento.

- La continua pérdida de turistas llegados al área, repercutiendo en los niveles de ocupación y rentabilidad de los empresarios del sector hotelero.

- Las modificaciones en la legislación turística introducidos por el Gobierno de Canarias a partir del año 2000 (decretos y leyes), obstaculizando enormemente el proceso de renovación de los establecimientos turísticos de Puerto de la Cruz ante la imposibilidad de que las instalaciones puedan cumplir la normativa vigente por su propia «naturaleza física» y el escaso suelo disponible del destino, ante la aplicación de los estándares turísticos.

- La escasa rentabilidad y competitividad del sector hotelero de Puerto de la Cruz derivados de los resultados del RevPar que demuestran una clara inadecuación de oferta-demanda a partir de una política de precios ajustados del sector que difiere de los precios del mercado turístico actual y de otros destinos vacacionales competidores, y una incapacidad manifiesta para la inversión en materia de norevación.

- La pérdida de plazas turísticas a través del cierre definitivo de establecimientos en los últimos años.

- Los elevados costes de la renovación y la dificultad para acceder a los instrumentos de financiación disponibles para modernizar las infraestructuras por parte de los empresarios locales, especialmente de las edificaciones gestionadas de forma independiente, normalmente con menor capacidad financiera para acometer una renovación integral.

- La falta de incentivos «reales» por parte de las administraciones públicas para favorecer la renovación de la oferta de alojamiento. 
- La elevada tasa de convivencia de usos turísticos-residencial en la infraestructura de alojamiento, que dificulta los procesos de renovación de la oferta, ante la diversidad de intereses entre los diferentes agentes implicados en la infraestructura para la toma de decisiones.

- La inestabilidad política en el seno de la Corporación local del destino que no ha favorecido un verdadero proceso de gobernanza en cuanto a la estrategia y planificación del área turística, repercutiendo en un continuo deterioro del espacio público e infraestructuras fundamentales para el desarrollo turístico.

- La falta de cooperación y consenso entre las distintas administraciones competentes en turismo, patronales de hoteleros y restantes actores del destino para articular medidas conjuntas en cuanto a la promoción y comercialización del destino.

- La crisis internacional de mediados del 2007.

Como resultado a la combinación de estos factores, Puerto de la Cruz, va a sufrir durante este período temporal una de las mayores crisis experimentadas a lo largo de toda su historia. Ello queda evidenciado en el gráfico 10, en relación con el número de licencias de obras expedidas para este último período de investigación, tanto para la modalidad hotelera como la extrahotelera. Esas cifras demuestran el proceso decadente a partir del año 2001, donde se observa un cambio de tendencia a la baja, coincidente con la entrada en vigor de nuevos reglamentos en materia turística en las islas, que ejemplifican el fracaso producido en materia de renovación durante estas fechas y que pone de manifiesto, el nivel de decadencia del sector hotelero a la par de lo que sucede en el propio destino turístico.

\section{Gráfico 10 \\ EVOLUCIÓN DEL NÚMERO DE LICENCIAS POR MODALIDAD ALOJATIVA EN PUERTO DE LA CRUZ Y SU RELACIÓN CON ALGUNOS FACTORES CONDICIONANTES (1999-2009)}

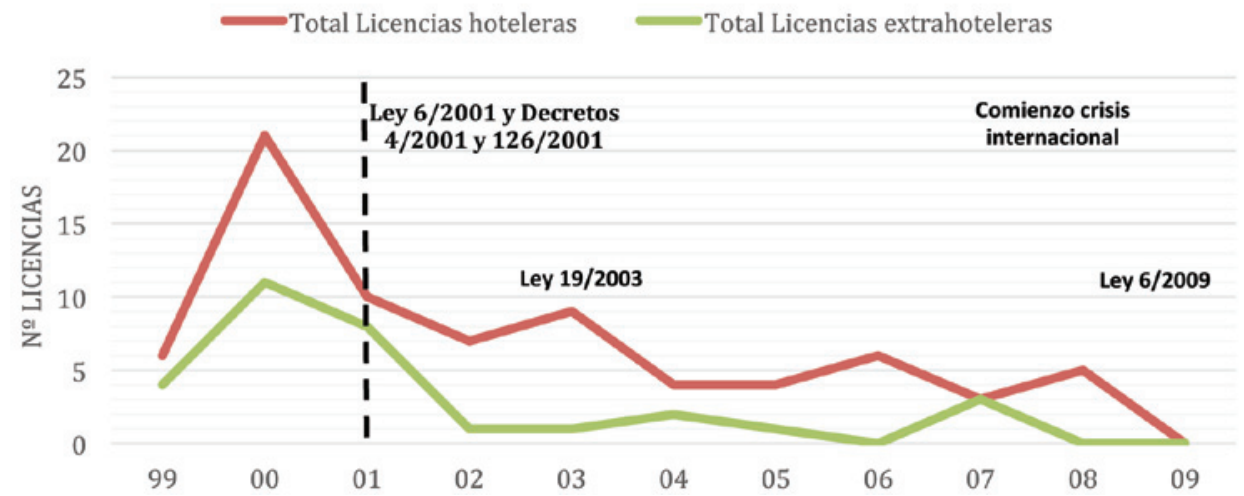

Fuente: elaboración propia a partir de las licencias urbanísticas de la Gerencia de Urbanismo y Archivo municipal del Ayuntamiento de Puerto de la Cruz. 
Todos los datos indican que el nuevo marco legislativo derivado de la denominada «moratoria turística» produjo una paralización del número de licencias en los siguientes años a su entrada en vigor. Así, durante los años 2003-2009 sólo se solicitaron licencias para 38 intervenciones. Se trató de un dato irrisorio si tenemos en cuenta el número de licencias expedidas durante los tres años anteriores y los aproximadamente 100 establecimientos turísticos que se contabilizaban en el destino para principios de siglo. Desde esta perspectiva, se produce un verdadero «recorte» en cuanto al número de licencias autorizadas y al escaso número de establecimientos que la solicitan.

Por tanto, la estrategia sigue centrándose tanto en obras de mantenimiento (alicatado y pavimentación) como de intervenciones para adecuar las edificaciones a la normativa vigente, en materia de seguridad. No obstante, si que hay que advertir, que será durante este período cuando se materializaron algunas de las intervenciones más importantes de toda la historia de Puerto de la Cruz. Así, destacamos, entre otras, las acometidas por las del hotel Botánico, H10 Tenerife Playa, Las Águilas, Vallemar, los Apartamentos Masaru, el Noelia Playa y especialmente el Hotel Atlantis, que supone un ejemplo de renovación integral con una inversión de 35 millones de euros (imagen 1). Estas operaciones de reforma suponen una excepción dentro de este período caracterizado por una parálisis del proceso de renovación.

\section{Imagen 1 \\ RESULTADO POST-OPERACIONAL DE LA RENOVACIÓN DE LA FACHADA DEL HOTEL ATLANTIS (2007-2011)}
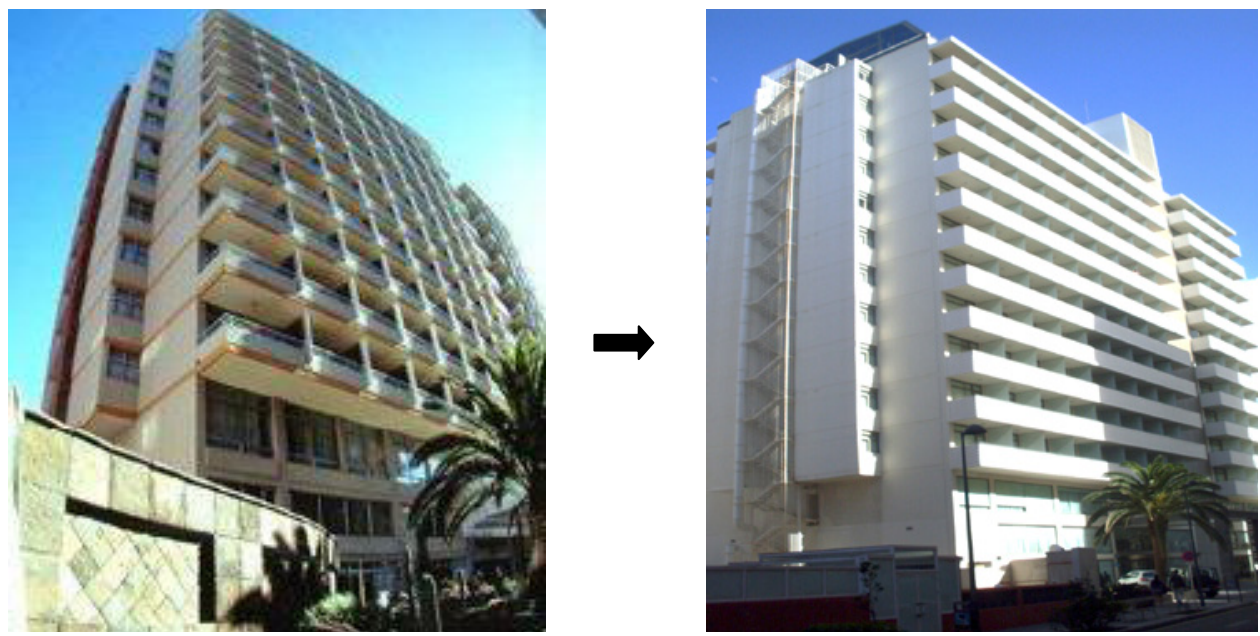

\section{CONCLUSIONES}

El proceso de renovación de la oferta turística de Puerto de la Cruz ha seguido una dinámica impropia de un destino turístico con una oferta hotelera antigua y con un alto grado de obsolescencia. Lejos de ajustarse a una realidad inherente -punto de partida para 
un replanteamiento del modelo turístico- basada en una reconversión sistemática de la infraestructura turística, se ha abordado un «ficticio», e insuficiente proceso de renovación basado en reformas, a modo de «parches», «una buena dosis de maquillaje» y varios «lavados de cara». Estos han intentado cubrir la falta de una estrategia coordinada de planificación y gestión de un destino turístico en situación de decadencia. Este escenario parte de ciertas premisas que resultan necesarias para comprender lo paradógico de lo expuesto con anterioridad y que se sintetizan en las siguientes cuestiones.

En primer lugar, se ha contabilizado 649 licencias de reforma de alojamientos turísticos durante el período de investigación (53 años), (teniendo en cuenta todas las instalaciones) lo que equivale a una media de 12 licencias por año. Ello da cuenta del pobre proceso de renovación turística, sobre todo, si tenemos en cuenta que la media ha sido de 9 actuaciones por establecimiento alojativo y muchas de estas edificaciones han cesado su actividad turística (via cierre y reconvertidas a residencial) a lo largo del tiempo. Por tanto, aproximadamente el $10 \%$ de los establecimientos alojativos existentes en la actualidad han acometido algún tipo de reforma edificatoria en el transcurso de un año. Este dato revela el claro déficit en cuanto al número de reformas necesarias para desarrollar un proceso de renovación «real» (gráfico 11$)$.

\section{Gráfico 11 \\ EVOLUCIÓN DEL NÚMERO DE LICENCIAS POR MODALIDAD (1955-2009)}

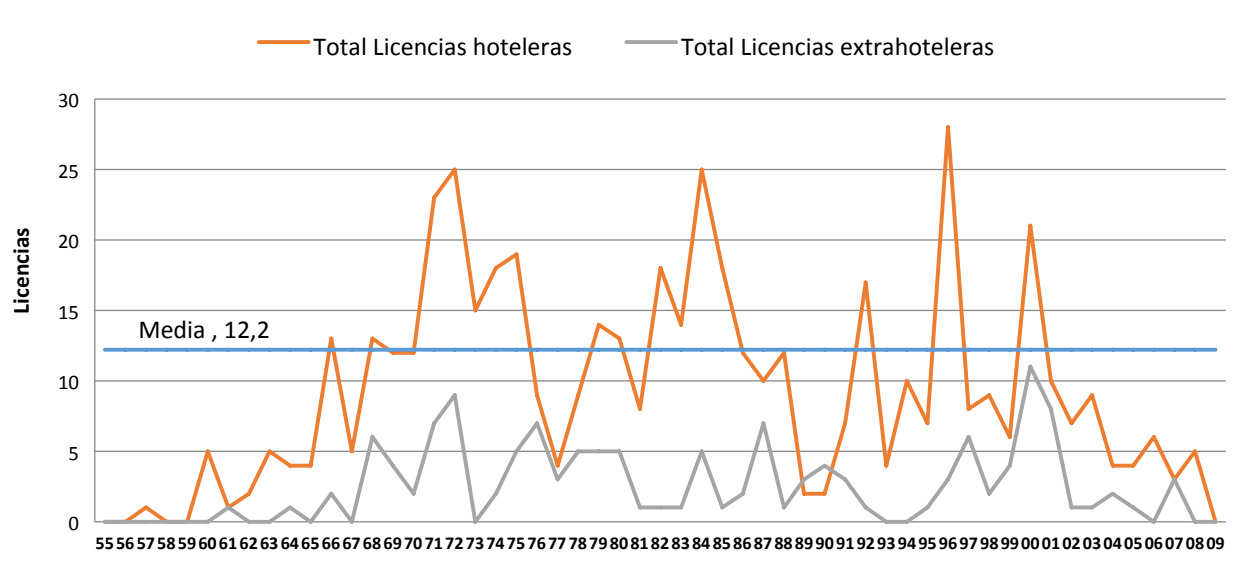

Fuente: Gerencia de Urbanismo y Archivo municipal del Ayuntamiento de Puerto de la Cruz. Elaboración propia.

En segundo lugar, teniendo en cuenta la Teoría de ciclo de vida de los destinos turísticos de Butler, existe una relación coherente entre el desarrollo de la fase de estancamiento, iniciada en los años 80, y la progresiva pérdida del número de reformas acontecidas en la infraestructura hotelera (gráfico 12). La evolución de su proceso de renovación edificatoria es «contra natura», encajando perfectamente con las diferentes fases que propone Butler, como ha planteado Álvarez (2004). 


\section{Gráfico 12}

\section{EVOLUCIÓN DE LICENCIAS DE REFORMA EN EL DESTINO TURÍSTICO PUERTO DE LA CRUZ Y SU RELACIÓN CON LA TEORÍA DE BUTLER}

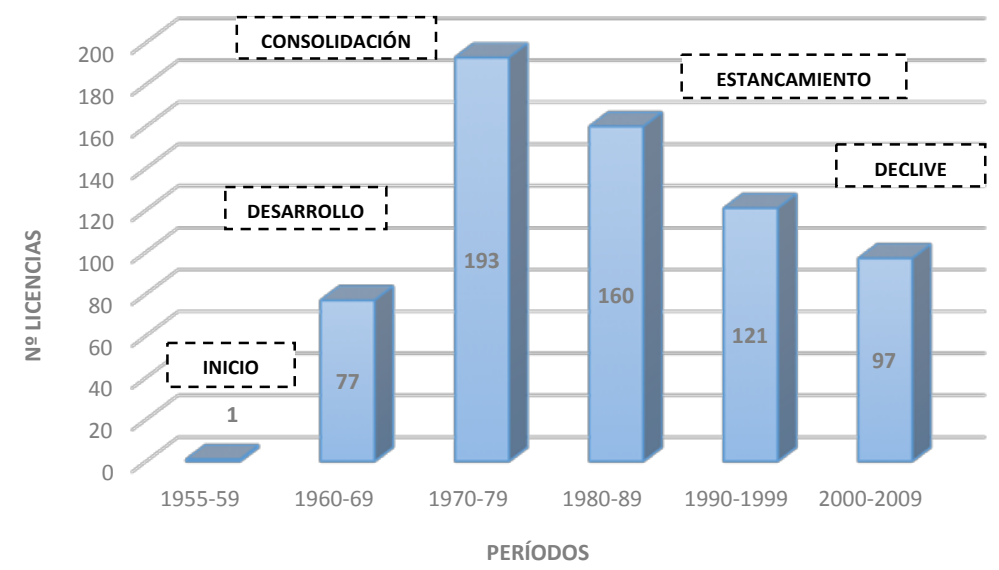

Fuente: Gerencia de Urbanismo y Archivo municipal del Ayuntamiento de Puerto de la Cruz. Elaboración propia.

En tercer lugar, las reformas que se han llevado a cabo en los establecimientos hoteleros se corresponden mayoritariamente a obras menores, de mantenimiento y conservación, representando el $80 \%$ del total de reformas. Se trata por tanto, de un proceso de renovación edificatoria marcado principalmente por las «tres pes» (pintar, pavimentar y parchear), con pequeñas obras de sustitución, acondicionamiento y decoración de los edificios turísticos $\mathrm{y}$, por tanto, lejos de acometer reformas que aumentasen el grado de calidad de los propios establecimientos hoteleros.

Por último, la situación de obsolescencia del destino y de numerosos establecimientos alojativos es consecuencia de una serie de condicionantes o factores, que no han posibilitado la renovación de la oferta de alojamiento. Así, atendiendo a los principios y objetivos en materia de política pública turística en Canarias, la renovación de la oferta turística en este destino no ha tenido el éxito esperado. Pese a lo expuesto, hay que valorar positivamente la constitución y gestión del Consorcio de Rehabilitación Turística de Puerto de la Cruz, que parece haber generado un cambio de tendencia y visos de esperanza para este sector con la firma de diferentes convenios con el empresariado hotelero; un total de 39 proyectos de rehabilitación, 2 proyectos de nueva construcción, un nuevo establecimiento de tipo rural y 11 proyectos con posibilidad de incorporarse al Plan de Modernización y Mejora de la competitividad turística.

Sin lugar a dudas, este aumento es consecuencia del compromiso adquirido por las diferentes partes (público-privado) en atajar de una forma contundente los problemas derivados del deterioro y obsolescencia de la oferta de alojamiento turístico del destino. No obstante, el tiempo y futuros trabajos que complementen y ahonden en materia de renovación edificatoria, determinaran el éxito o fracaso del mismo, y por ende, la renovación del destino turístico. 


\section{BIBLIOGRAFÍA}

ÁLVAREZ ALONSO, A. (2004): «El ciclo de vida de los destinos turísticos litorales», en Álvarez Alonso, A.; Hernández Hernández, J. y Simancas Cruz, M. R. (Dir. y Coord.). Turismo y territorio en la sociedad globalizada. Ayuntamiento de la Villa de Adeje / Instituto Pascual Madoz del Territorio, Urbanismo y Medio Ambiente. Universidad Carlos III. Santa Cruz de Tenerife, pp. 124-155.

AGARWAL, S. (2002): «Restructuring seaside tourism. The resort lifecycle», Annals of Tourism Research, vol. 29, pp. 5-55.

AGARWAL, S. (2006): «Coastal Resort Restructuring and the TALC Model», en Butler, R.W. (Ed.). The tourism area life cycle. Conceptual theoretical Issues, Channel View Publications.

ANTON, S. (2004): «De los procesos de diversificación y cualificación a los productos turísticos emergentes. Cambios y oportunidades en la dinámica reciente del turismo litoral», Papeles de Economía Española, n 102 , pp. 316-332.

ANTON, S. (2011): «Dinámicas de reestructuración de los destinos turísticos litorales del Mediterráneo. Perspectivas y condicionantes», en Renovación de destinos turísticos consolidados, coord. por Diego López, Valencia, Tirant Lo Blanch, pp. 23-40.

ANTON, S. (2012): 10 Lecciones sobre turismo. El reto de reinventar los destinos. Barcelona, Editorial Planeta.

ARCHER, B. (1995): «Importance of tourism for the economy of Bermuda». Annals of Tourism Research, vol. 22, (4), pp. 918-930.

ASHOTEL (1985): «La hostelería canaria. Solidaridad sectorial. Cooperativismo. Solución a una crisis». El turismo en Canarias. IV Jornadas de Estudios Económicos Canarios, pp. 139-155.

BUTLER, R.W. (1980): «The Concept of Tourist Area Cycle of Evolution. Implications for Management of Resources», Canadian Geographer, $\mathrm{n}^{\circ}$ 24, pp. 5-12.

BUTLER, R.W. (2006a): The tourist area life cycle. Applications and Modifications, Vol. I, Clevedon, Channel View.

BUTLER, R.W. (2006b): The tourist area life cycle. Conceptual and Theoretical Issues, Vol. II, Clevedon, Channel View.

CÁCERES MORALES, E. (2001): Génesis y desarrollo del espacio turístico de Canarias. Universidad de Las Palmas de Gran Canaria y Gobierno de Canarias.

CHINCHILLA PEINADO, J.A. (2009); «La rehabilitación de los establecimientos turísticos alojativos como manifestación del desarrollo urbanístico sostenible. El ejemplo de Canarias», Práctica urbanística, n 87, pp. 64-77.

CLAVER CORTÉS, E., MOLINA AZORÍN, J.F., y PEREIRA MOLINER, J. (2007): «Competitividad en turismo de masas». Annals of tourism Research en Español, vol. 9, (2), pp. 266-286.

CLEGG A. y ESSEX S. (2000): «Restructuring in Tourism. The Accommodation Sector in a Major British Coastal Resort». International Journal of Tourism Research, vol. 2 (2), pp. 77-95

DONAIRE, J.A., y MUNDET I CERDÁN, Ll. (2001): «Estrategias de reconversión turística de los municipios litorales catalanes», Papers de Turisme, n 29, pp. 50-66. 
DORTA RODRÍGUEZ, A. (2010): «Los sistemas de calidad turística como estrategia de renovación de la oferta alojativa en destinos turísticos maduros. El caso de Puerto de La Cruz (Tenerife, España)», en HERNÁNDEZ MARTÍN, R. y SANTANA TALAVERA, A. (Coord.). Destinos turísticos maduros ante el cambio. Instituto Universitario de Ciencias Políticas y Sociales, Universidad de La Laguna. San Cristóbal de La Laguna, pp. 161-182.

DORTA RODRÍGUEZ, A. (2011): «Crisis económica y cierre de establecimientos alojativos en destinos turísticos consolidados. El caso de Puerto de La Cruz (Tenerife)», en Espacios y destinos turísticos en tiempos de globalización y crisis. Madrid, Asociación de Geógrafos Españoles, vol. II, pp. 183-197.

DORTA RODRÍGUEZ, A. (2013): «Algunos apuntes sobre la renovación hotelera como estrategia de reestructuración de destinos turísticos consolidados», Revista Turismo (Escuela Universitaria de Turismo Iriarte), vol. 3-4, pp. 33-37.

DORTA RODRÍGUEZ, A. (2015): Análisis del proceso de renovación de la oferta turística de alojamiento en destinos consolidados: el caso de Puerto de la Cruz (Tenerife). (Tesis doctoral). Servicio de publicaciones. Universidad de La Laguna. San Cristóbal de La Laguna.

DORTA RODRÍGUEZ, A., SIMANCAS CRUZ, M.R. y GARCÍA CRUZ, J.I. (2011): «La renovación del Hotel Beatriz Atlantis \& Spa (Puerto de la Cruz, Islas Canarias). Un ejemplo de recualificación de la oferta de alojamiento obsoleta en destinos turísticos consolidados», en Seminario Internacional sobre renovación y reestructuración de destinos turísticos consolidados del litoral. Alicante del 24-25 de noviembre

DURO, J.A. (2012): «La transformación del modelo de implantación hotelera», en El reto de reinventar los destinos, Barcelona, Editorial Planeta, pp. 153-168.

FUSTER, B., LILLO, A., MARTÍNEZ, C., y RAMÓN, A. (2010). Crecimiento internacional de cadenas hoteleras vacacionales españolas desde una perspectiva global. Un estudio de casos. Cuadernos de Turismo, no 25, (2010); pp. 69-97.

GARCÍA CRUZ, J.I. (2013): El impacto territorial del tercer boom turístico de Canarias. (Tesis doctoral). Servicio de publicaciones. Universidad de La Laguna. San Cristóbal de La Laguna.

GONZÁLEZ REVERTÉ, F. (2012): «El modelo de reestructuración turística de la Costa Daurada», en Renovación y reestructuración de destinos turísticos en áreas costeras: marco de análisis, procesos, instrumentos y realidades / coord. por José Fernando Vera Rebollo, Isabel Rodríguez Sánchez, pp. 219-241.

GONZÁLEZ HERNÁNDEZ, M., LEÓN GONZÁLEZ, C. J. y PADRÓN FUMERO, N. (2006): «Obsolescencia y políticas de renovación medioambiental en el sector turístico», Cuadernos económicos de ICE, $\mathrm{n}^{\circ}$ 71, pp. 153-176.

GONZÁLEZ LEMUS, N., HERNÁNDEZ PÉREZ, M., y SÁNCHEZ GARCÍA, I. (2005): El Puerto de la Cruz. De ciudad portuaria a turística. Centro de Iniciativas Turísticas de Puerto de la Cruz, Puerto de la Cruz (Tenerife).

GONZÁLEZ LEMUS, N. y HERNÁNDEZ PÉREZ, M. (2010): El turismo en la historia del Puerto de la Cruz. Escuela Universitaria de Turismo Iriarte.

GUTIÉRREZ, D. y OREJA, J.R. (1998): «Bases para el diseño de estrategias de fidelización en destinos turísticos maduros», en VII Congreso Nacional de ACEDE, Las Palmas. 
IVARS BAIDAL, J.A., RODRÍGUEZ SÁNCHEZ, I. y VERA REBOLLO J.F. (2013): «The evolution of mass tourism destinations. New approaches beyond deterministic models in Benidorm (Spain)», Tourism Management, vol. 34, 2013, pp. 184-195.

JOHNSTON, C.S. (2001): «Shoring the Foundations of the Destination Life Cycle Model, Part 1. Ontological and Epistemological Consideratinos», Tourism Geographies, vol. 3 (1), págs. 2-28.

LEDESMA GONZÁLEZ, O. (2012): El modelo turístico de Puerto de la Cruz. Presente y futuro. Nivaria Ediciones, San Cristóbal de La Laguna.

LÓPEZ OLIVARES D. y FERRERES BONFILL, J.B. (2011): «La reestructuración de los destinos consolidados del litoral castellonense. El caso de Benicàssim (Castellón, Comunitat Valenciana)», en Actas del Seminario Internacional sobre renovación y reestructuración de destinos turísticos consolidados del litoral. Alicante del 24-25 de noviembre.

MARTIN AZAMI, D. (2005): Determinantes estratégicos de la fidelidad del turista en destinos maduros. Tesis de Doctoral. Universidad de La Laguna.

MARTIN MARTIN, V.O. (1998): «El Valle de la Orotava. Un destino turístico con una larga tradición histórica», en La actividad turística española en 1996 (Edición 1997). AECIT, Nexo Ediciones. Madrid.

MCNEILL, D. (2008): «The hotel and the city», Progress in Human Geography, vol.32 (3) pp. 383-398.

MONTERO, I. y OREJA, J.R. (1996): «La excelencia turística y calidad hotelera como objetivo de un destino turístico maduro. El caso de Puerto de la Cruz (Tenerife)», Anales de Economía y Administración de Empresas, n ${ }^{\circ}$, pp. 71-84.

OBIOL MENERO, E. y FERRANDIS MARTÍNEZ, A. (2012): «Gandía y sus prácticas de renovación turística», en Renovación y reestructuración de destinos turísticos en áreas costeras: marco de análisis, procesos, instrumentos y realidades, coord. por José Fernando Vera Rebollo, Isabel Rodríguez Sánchez, Universidad de Alicante, pp. 375-398.

PARRA LÓPEZ E., MELCHIOR NAVARRO, M. y FUENTES MEDINA, L. (2010): «Dinámicas de transformación de un destino turístico maduro», en Destinos turísticos maduros ante el cambio. Reflexiones desde Canarias, coord. por Raúl Hernández Martín, Agustín Santana Talavera, pp. 217-232.

PÉREZ, C. y PÁEZ, A.I. (2014): «El turismo de eventos y reuniones en destinos turísticos maduros: un pilar para la reconversión del producto turístico de Puerto de la Cruz (Tenerife)», Investigaciones Turísticas, $n^{\circ}$ 7, pp. 102-135.

POTTER, R. y PHILLIPS, J. (2004): «The Rejuvenation of Tourism in Barbados 19932003. Reflections on the Butler model», Geography. vol. 89 (3), pp. 240-247.

PRIESTLEY, G. y MUNDET, LL. (1998): «The post-stagnation phase of the resort cycle», Annals of Tourism Research, vol. 25, pp. 85-111.

SANTOS PAVÓN, E.L. y FERNÁNDEZ TABALES, A. (2010): «El litoral turístico español en la encrucijada. Entre la renovación y el continuismo»; Cuadernos de Turismo, $\mathrm{n}^{\circ} 25$, pp. 185-206.

SIMANCAS CRUZ, M.R. (2010): «La renovación edificatoria de la oferta turística de alojamiento en destinos consolidados. La experiencia de Canarias», Cuadernos de Geografía (Universitat de Valencia), nº 87, pp. 23-44. 
SIMANCAS CRUZ, M.R. (2011): «El fracaso de la renovación de áreas turísticas consolidadas de litoral a través de la sustitución de la oferta de alojamiento obsoleta. La experiencia de las Islas Canarias», Cuadernos de Turismo, nº 27, pp. 869-899.

SIMANCAS CRUZ, M.R. (2012): Evaluando políticas públicas de renovación de destinos turísticos maduros: el proceso de reconversión turística de Canarias, en VERA REBOLLO, F. y RODRÍGUEZ SÁNCHEZ, I. (Eds.): Renovación y restructuración de destinos en áreas costeras. Marco de análisis, procesos, instrumentos y realidades. Colección: Desarrollo Territorial, 11. Universitat de València, pp. 163-200.

SIMANCAS CRUZ, M.R. y GARCÍA CRUZ, J.I. (2010): «El impacto territorial de las estrategias de mejora de la calidad de los destinos maduros. La aplicación de estándares edificatorios a los alojamientos turísticos», en HERNÁNDEZ MARTíN, R.; SANTANA TALAVERA, A. (Coord.). Destinos turísticos maduros ante el cambio. Instituto Universitario de Ciencias Políticas y Sociales, Universidad de La Laguna. San Cristóbal de La Laguna, pp. 161-182.

SIMANCAS CRUZ, M.R. y GARCÍA CRUZ, J.I. (2013): La dimensión territorial de la residencialidad en las áreas turísticas consolidadas de Canarias, Boletín de la Asociación de Geógrafos Españoles, nº 63, pp. 271-299.

VERA REBOLLO, J.F. y BAÑOS, C.J. (2010): «Renovación y reestructuración de los destinos turísticos consolidados del litoral. Las prácticas recreativas en la evolución del espacio turístico, Boletín de la Asociación de Geógrafos Españoles, no 53 pp. 329-353.

VERA REBOLLO, J.F., (Coord.), LÓPEZ PALOMEQUE, F., MARCHENA, M. y ANTÓN CLAVÉ, S. (2011): Análisis territorial del turismo y planificación de destinos turísticos. Valencia, Tirant lo Blanch.

VERA REBOLLO, J.F., RODRÍGUEZ, I. y CAPDEPÓN, M. (2010): «Reestructuración y competitividad en destinos maduros de sol y playa. La renovación de la planta hotelera de Benidorm», en XIII Congreso Internacional de Turismo, Universidad y Empresa. Universitat Jaume I, Castellón. 
